\title{
The Bottlenose Dolphin (Tursiops truncatus) as a Model to Understand Variation in Stress and Reproductive Hormone Measures in Relation to Sampling Matrix, Demographics, and Environmental Factors
}

\author{
Randall S. Wells \\ Chicago Zoological Society \\ c/o Mote Marine Lab \\ 1600 Ken Thompson Parkway \\ Sarasota, FL 34236 \\ phone: (941) 388-2705 fax: (941) 388-4223 email: rwells@mote.org \\ Award Number: N000141110542 \\ http://sarasotadolphin.org
}

\section{LONG-TERM GOALS}

Our overarching goal is to develop indicators and methods to quantify chronic stress in bottlenose dolphins. Much research has focused on the stimuli which induce stress in marine mammals, as well as the hormonal mediators of the stress response. Stress may be induced by a variety factors, including noise, pollutant or toxin exposure, presence of predators, loss of prey, and/or habitat changes. The stress response is complex and difficult to study experimentally in marine mammals due to ethical and logistical considerations, but has been well characterized in other laboratory mammal species. In mammals (including marine mammals) and other vertebrates, the stress response has two modes of operation: 1) the fast mode involves the rapid release of fast-acting agents that drive the fight-or-flight response, such as catecholamines, which excite the hypothalamic-pituitary-adrenal (HPA) axis and initiate a hormonal cascade that ends in the secretion of glucocorticoids (GCs) by the adrenal cortex; and 2) the delayed but more sustained response driven by GCs that coordinates brain and body functions to cope with stress and facilitate recovery, adaptation, and re-establishment of homeostasis

While the HPA axis and physiological processes driven by the GCs are essential for an individual's ability to respond and adapt to stress, prolonged elevation of $\mathrm{GC}$ hormones can lead to chronic immune suppression and inhibition of other energy-expending hormonal systems, including disruption of reproductive function along the HPA axis, all of which may cumulatively lead to decreased survival and/or inability to reproduce. For this reason, developing indicators and methods to quantify stress in marine mammals is essential for understanding risks and long-term consequences for populations.

\section{OBJECTIVES}

Using the bottlenose dolphin as a model species, specific objectives for this project are:

1. Determine correlation of hormone measures between blood and blubber 


\section{Report Documentation Page}

Form Approved

OMB No. 0704-0188

Public reporting burden for the collection of information is estimated to average 1 hour per response, including the time for reviewing instructions, searching existing data sources, gathering and maintaining the data needed, and completing and reviewing the collection of information. Send comments regarding this burden estimate or any other aspect of this collection of information,

including suggestions for reducing this burden, to Washington Headquarters Services, Directorate for Information Operations and Reports, 1215 Jefferson Davis Highway, Suite 1204, Arlington

VA 22202-4302. Respondents should be aware that notwithstanding any other provision of law, no person shall be subject to a penalty for failing to comply with a collection of information if it

does not display a currently valid OMB control number.

1. REPORT DATE

30 SEP 2014

4. TITLE AND SUBTITLE

The Bottlenose Dolphin (Tursiops truncatus) as a Model to Understand Variation in Stress and Reproductive Hormone Measures in Relation to Sampling Matrix, Demographics, and Environmental Factors

6. $\operatorname{AUTHOR}(\mathrm{S})$

7. PERFORMING ORGANIZATION NAME(S) AND ADDRESS(ES)

Chicago Zoological Society,c/o Mote Marine Lab,1600 Ken Thompson Parkway,Sarasota,FL,34236

9. SPONSORING/MONITORING AGENCY NAME(S) AND ADDRESS(ES)
3. DATES COVERED

00-00-2014 to 00-00-2014

5a. CONTRACT NUMBER

5b. GRANT NUMBER

5c. PROGRAM ELEMENT NUMBER

5d. PROJECT NUMBER

5e. TASK NUMBER

5f. WORK UNIT NUMBER

8. PERFORMING ORGANIZATION

REPORT NUMBER

10. SPONSOR/MONITOR'S ACRONYM(S)

11. SPONSOR/MONITOR'S REPORT $\operatorname{NUMBER}(\mathrm{S})$

12. DISTRIBUTION/AVAILABILITY STATEMENT

Approved for public release; distribution unlimited

13. SUPPLEMENTARY NOTES

14. ABSTRACT

15. SUBJECT TERMS

16. SECURITY CLASSIFICATION OF:

a. REPORT

b. ABSTRACT

unclassified

unclassified

c. THIS PAGE unclassified
17. LIMITATION OF ABSTRACT

Same as

Report (SAR)
18. NUMBER OF PAGES

5 19a. NAME OF

RESPONSIBLE PERSON

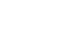


2. Develop a comprehensive understanding of factors that influence stress hormone levels and establish reference intervals, determining necessary stratifications by sex, age and/or sampling season.

3. Examine relationships among the various hormone measures, and conduct preliminary screening analysis to examine potential relationships between the stress hormones and other health measures.

\section{APPROACH}

\section{Field Studies}

The Chicago Zoological Society's (CZS) "natural laboratory" situation in Sarasota Bay, Florida provides unique opportunities to address questions related to stress, as a resident population of bottlenose dolphins has been studied for more than 40 years, relying upon methods which include capture-release health assessments. Stress and reproductive hormones (cortisol, aldosterone, thyroid, testosterone, progesterone) have been routinely measured in blood serum as part of the health assessment, which also includes a complete physical examination, morphometric measurements, hearing tests, and biological sampling of skin, blubber, urine, feces, gastric contents, and blowhole. These tissue samples are analyzed for a broad suite of diagnostics. We have leveraged this existing collection of data and also conducted additional sampling during Sarasota Bay health assessments over the past 3 years to help meet our proposed objectives. We have also included existing data from prior (2009) capture-release health assessments along the Georgia coast.

In addition, recent work by our collaborative team has supported the use of blubber as a sampling matrix for measuring hormone concentrations. Blubber provides an advantage in that samples can be readily obtained using remote biopsy, which is relatively inexpensive and entails less harassment compared to capture-release sampling. In addition, while the logistics of capturerelease sampling generally limit its utility to investigations of coastal cetaceans, remote biopsy has the potential to be a powerful tool for investigations across a range of habitats, from estuarine to nearshore and pelagic populations. To elucidate potential seasonal variation in blubber hormone measures, remote biopsy samples have been collected to across 4 seasons in estuarine and coastal waters near Charleston, South Carolina, and across 2 seasons in the Ashepoo, Combahee and Edisto (ACE) Basin, also in South Carolina.

\section{Laboratory Analyses}

Hormone concentrations (cortisol, aldosterone, reproductive and thyroid hormones) in serum samples have been analyzed by Cornell's Animal Health Diagnostic Center (AHDC)

Endocrinology Laboratory. Cortisol and reproductive hormone concentrations in blubber samples matched to serum samples from the capture-release health assessments have been analyzed by Dr. Nick Kellar's (NMFS/SWFSC) laboratory using commercially available enzyme-immuno (EIA) assay kits.

In 2013, we initiated collaboration with Dr. Ashley Boggs (National Institute of Standards and Technology) to explore alternative methods for the detection of hormones in blubber. Dr. Boggs is in the process of developing and validating a new method using pressurized fluid extraction (PFE) and gel permeation chromatography (GPC) to liquid chromatography tandem mass spectrometry (LC-MSMS) to extract and directly quantify multiple classes of hormones from a single sample. 
Once Dr. Boggs has completed validation of this method, she will perform the analysis of our seasonal remote biopsy samples, thus providing us information on a much broader suite of hormones for our samples.

The project is a collaborative effort led by Dr. Lori Schwacke (NOAA/National Ocean Service (NOS)/National Centers for Coastal Ocean Science (NCCOS)) and Dr. Randall Wells (Chicago Zoological Society). Other collaborators and co-PIs are Eric Zolman, NOAA/NOS/NCCOS, Dr. Nicholas Kellar, NOAA/National Marine Fisheries Service (NMFS), Southwest Fisheries Science Center, Dr. Patricia Rosel, NOAA/NMFS Southeast Fisheries Science Center, Dr. Teri Rowles, NOAA/NMFS, Office of Protected Resources, Dr. Leslie Hart, NOAA/NOS/NCCOS, and Dr. Ashley Boggs, NIST.

\section{WORK COMPLETED}

All field studies been completed. Matched blood and blubber samples were collected from dolphins in Sarasota Bay during May $2009(\mathrm{n}=20)$, May $2010(\mathrm{n}=10)$, May $2011(\mathrm{n}=15)$, and May $2012(\mathrm{n}=16)$. Additional blood samples, without blubber, were collected in July $2012(\mathrm{n}=10)$. More than 2,100 hormone measures previously obtained for Sarasota Bay dolphins were applied to this project. Remote biopsy sampling to collect blubber samples across seasons was conducted during Fall 2011 and Winter, Spring, Summer 2012 in waters near Charleston, SC, and conducted in the ACE Basin during Winter and Summer 2012. In total, 118 blubber samples were collected for hormone analysis.

With the exception of the analysis of seasonal blubber samples, all laboratory analyses have been completed. The analysis of the remaining samples will be completed once development and validation of the LC-MSMS method has been completed by NIST.

\section{Progress on LC-MSMS Method Development}

Previous work at NIST on organic contaminants in blubber has shown the effectiveness of lipid extraction from tissue using PFE and GPC. The PFE is better able to extract total lipid from solid tissues than other extraction methods, which yields a better recovery of target lipophilic analytes. GPC then utilizes size exclusion chromatography to separate large lipid proteins from small molecules of interest such as contaminants. Analytes of interest can then be analyzed using LC-MS/MS which has the advantage over immunoassay technologies of using highly specific mass and fragmentation patterns of the analyte to ensure measurement of the exact target. Using the methods developed for the analysis of organic contaminants in blubber, we have applied this technology to explore the extraction and measurement of 22 steroid hormones from a single blubber sample analysis, which has not been attempted previously.

Initial method development was conducted on blubber from stranded pilot whales and dolphins. While the stress hormones are expected to be higher in a sample from a stranded animal versus a dartbiopsied animal, large pieces of blubber were required for repeat analyses during method development and validation. Therefore we used $0.4-0.5 \mathrm{~g}$ (approximately one half of a dart biopsy) of full depth blubber from stranded animals to develop the method.

Extraction efficiencies are currently being processed and analyzed, and in all, initial extracts were scanned for 22 target hormones and hormone metabolites. Currently, testosterone, cortisol, 11deoxycortisol, and aldosterone are being detected at measureable concentrations inmale bottlenose dolphin blubber samples. Additional target analytes include androstenedione, adrenosterone, 
pregnenolone, corticosterone, 21-deoxy-cortisol, 17-hydroxy-pregnenolone, 17-hydroxy-progesterone, dehydroepiandrosterone, dihydrotestosterone, ketoprogesterone, and allopregnenolone. Female bottlenose dolphin samples remain to be tested, but progesterone and cortisol were clearly detected in female pilot whale samples during method validations, and additional hormones may be measured with the final analysis. Initial analyses of pilot whale blubber did not detect any estrogens (estradiol, estriol, estrone and equilenin), but further analysis using bottlenose dolphin samples are merited.

Cortisol concentrations in the blubber using the PFE-LC-MS/MS method are lower than would be expected according to the work of the Kellar laboratory. Currently, an extraction efficiency test is underway to determine if the measured concentrations are indeed in low concentration in the blubber, or if a loss of hormone occurs in the extraction process yielding a low signal at LC-MS/MS measurement. One potential issue could be the cross-reactivity of 11-deoxycortisol as a cortisol signal using enzyme immunoassays. Given our preliminary data showing large concentrations of 11deoxycortisol in the bottlenose dolphin blubber samples run using PFE-LC-MS/MS, there may be cortisol metabolites that are more prevalent in the blubber than in circulation that are interfering with measurement using enzyme immunoassay. Dr. Boggs and Dr. Kellar are working together to determine the absolute concentrations of cortisol in blubber by using Dr. Kellar's extraction method and following up with both enzyme immunoassay measurement and LC-MS/MS measurement on the same extract.

\section{RESULTS}

In FY14, we published a manuscript in Environmental Science and Technology [1] that compares stress hormone and other health data between Sarasota Bay dolphins and dolphins from an area that was heavily oiled following the Deepwater Horizon (DWH) oil spill. This publication describes important results for the DWH Natural Resource Damage Assessment, and demonstrates the importance of understanding responses in bottlenose dolphins during acute stress events such as capture-release events. The work conducted under this ONR project, as well as from prior research by the Sarasota Dolphin Research Program, was instrumental in building this understanding, without which the interpretation of cetacean stress hormones and related health data following environmental exposures or other chronic stress events would not be possible.

Other data analyses have also been completed and were previously described in the FY13 Annual Report. In brief, statistical methods were used to evaluate demographic and sampling factors contributing to observed differences in serum concentrations of adrenal hormones (i.e. cortisol, aldosterone), and relationships among these various hormones in bottlenose dolphins sampled in Sarasota Bay, Florida, USA (2000-2012). Results of the statistical tests to identify factors influencing hormone concentrations and nonparametric bootstrap methods were used to develop stratified $90^{\text {th }}$ and $95^{\text {th }}$ percentile reference intervals for each hormone constituent. The reference intervals are important for identification of "abnormal cases" as part of future interpretation of adrenal hormone measures across cetacean populations exposed to varying types and degrees of stressors. These results have been summarized in a manuscript that is in the final stages of co-author review before submission to a peerreviewed journal.

In addition, models to investigate the dynamics of cortisol in different dolphin tissues were developed and parameterized using cortisol measurements from blubber and blood relative to handling time in live-captured individuals. The developed models were the first to suggest that blubber cortisol concentration correlates with the cortisol level in blood, but with a time lag. This suggests that when 
biopsying, the increase in cortisol due to the act of sampling has little effect on blubber cortisol levels (assuming that action occurs within minutes to tens of minutes). Therefore, remote biopsy sampling may provide a good measurement of baseline cortisol in free ranging bottlenose dolphins. A manuscript describing these analyses is currently in preparation.

\section{IMPACT/APPLICATIONS}

Our results to date provide tremendous new insight into the dynamics of cortisol in both blood and blubber for dolphins experiencing acute stress, as well as provide critical baseline information on cortisol and other hormone concentrations in wild dolphin populations. This understanding is absolutely essential for future stress studies in dolphins and other cetaceans in order to appropriately interpret stress hormone measures. Furthermore, the reference intervals produced by this study provide the basis for evaluation of animal health that is necessary for future population assessments.

\section{RELATED PROJECTS}

A matching project is being conducted under the leadership of Dr. Lori Schwacke of the NOAA/National Ocean Service Hollings Marine Laboratory (Project No. N0001412IP20053). Data analyses are being performed jointly. The remaining analyses will be completed under Dr. Schwacke's grant, as all of the work proposed for the Chicago Zoological Society portion of the project has been completed and the funds have been fully expended.

\section{PUBLICATIONS}

1. Schwacke LH, Smith CR, Townsend FI, Wells RS, Hart LB, et al. (2014) Health of Common Bottlenose Dolphins (Tursiops truncatus) in Barataria Bay, Louisiana, Following the Deepwater Horizon Oil Spill. Environmental Science \& Technology 48: 93-103. 